\title{
Dyeing Para-Aramid Textiles Pretreated with Soybean Oil and Nonthermal Plasma Using Cationic Dye
}

\author{
Mary Morris ${ }^{1}$, Xiaofei Philip Ye ${ }^{1, *(1)}$ and Christopher J. Doona ${ }^{2,3}$ \\ 1 Department of Biosystems Engineering and Soil Science, The University of Tennessee, Knoxville, TN 37996, USA; \\ maramorr@vols.utk.edu \\ 2 U.S. Army Combat Capabilities Development Command-Soldier Center, Natick, MA 01760, USA; \\ doonac@mit.edu \\ 3 Research Affiliate, Massachusetts Institute of Technology-Institute for Soldier Nanotechnologies, \\ 77 Massachusetts Ave., NE47-4F, Cambridge, MA 02139, USA \\ * Correspondence: xye2@utk.edu; Tel.: +1-(865)-974-7129
}

Citation: Morris, M.; Ye, X.P.; Doona, C.J. Dyeing Para-Aramid Textiles Pretreated with Soybean Oil and Nonthermal Plasma Using Cationic Dye. Polymers 2021, 13, 1492. https:// doi.org/10.3390/polym13091492

Academic Editors: Tarek M.

Abou Elmaaty and Maria

Rosaria Plutino

Received: 18 April 2021

Accepted: 3 May 2021

Published: 6 May 2021

Publisher's Note: MDPI stays neutral with regard to jurisdictional claims in published maps and institutional affiliations.

Copyright: (c) 2021 by the authors. Licensee MDPI, Basel, Switzerland. This article is an open access article distributed under the terms and conditions of the Creative Commons Attribution (CC BY) license (https:/ / creativecommons.org/licenses/by/ $4.0 /$ )

\begin{abstract}
The increasing use of functional aramids in a wide array of applications and the inert nature of aramids against conventional dye and print methods requires developing new dyeing methods. This study aims to use environmentally friendly method with a cationic dye as an alternative for dyeing para-aramid fabrics. Experiments used a multi-factorial design with functions of pretreatment, dye solvent (water and/or glycerol) and auxiliary chemical additives (swelling agent and surfactant) and a sequential experimentation methodology. The most effective dyeing procedures involved the following steps: (i) pretreatments of the fabrics with soybean oil and nonthermal plasma (NTP), (ii) using water at $\mathrm{T}=100{ }^{\circ} \mathrm{C}$ as the dye solvent, and (iii) omitting other chemical additives. With a commercial cationic dye, these conditions achieved a color strength in $\mathrm{K} / \mathrm{S}$ value of 2.28, compared to $\sim 1$ for untreated samples. FTIR analysis revealed that a functional network formed on the fibers and yarns of the fabrics by chemical reactions of excited plasma species with double bonds in the soybean oil molecules was responsible for significantly improving the color strength. These results extend the potential uses of a renewable material (soybean oil) and an environmentally friendly technology (NTP) to improve the dyeing of para-aramid textiles and reduce the use of harsh dye chemicals.
\end{abstract}

Keywords: soybean oil; glycerol; nonthermal plasma; para-aramid textiles; cationic dye

\section{Introduction}

Aramid (portmanteau combining aromatic and polyamide) fibers are high-performance fibers with properties of a high tensile strength, high melting point, chemical resistance to a range of organic solvents and exceptional flame resistance [1]. Consequently, aramid fibers have found wide applications in various technical areas, including textiles for apparel such as body armor (bullet-proof vests and helmets), puncture-resistant correctional wear, fire-protective clothing and sportswear and other applications such as brake pads, gaskets, hot-air filters, industrial belts and ropes, reinforced composites, tire cords and the strength member in fiber optics.

There are two main types of aramids: meta-aramids and para-aramids, and these two groups have different properties due to differences in their molecular structures. At the fundamental level, para-aramid fibers consist of poly(p-phenylene terephthalamide) molecules estimated to be $230 \mathrm{~nm}$ long, with stiff para-linked aromatic rings and densely arranged hydrogen bond donors and acceptors throughout their backbones. This inherent molecular rigidity, combined with strong intermolecular hydrogen bonding interactions, enables the molecules to achieve excellent alignment with their neighbors, resulting in a highly anisotropic unit cell consisting of covalent bonds, hydrogen bonds and van der Waals interactions along each fundamental axis, forming a highly crystalline structure [1]. The building-block molecules of meta-aramid are poly(m-phenylene isophthalamide) that 
bind via meta-linked aromatic rings to result in a semi-crystalline fiber with the molecular chain oriented along the fiber axis.

With the increasing array of applications using aramids, there is also the need to find alternative methods for dyeing aramid textiles. It has been a significant challenge to dye or print aramid fabrics to a high color strength using conventional dyeing and printing methods, especially for continuous filament para-aramids due to their highly crystalline structure and chemical inertness. Currently, the color of woven aramid materials uses primarily solution dyeing methods, in which the coloring of the yarns in the woven or knit fabric is determined by adding colorant to the polymer dope at the time the aramid filament is produced, thereby limiting the color options for the fabrics and their use in potential new applications. Various surface modification methods have been attempted to improve the dyeing of aramids, including chemical treatments with strong acids [2,3] and auxiliary additives [4], physical approaches using $\mathrm{UV} / \mathrm{O}_{3}$ irradiation [5] or nonthermal plasma [6], and chemical grafting using poly(acrylic acid) [7] or a diblock copolymer derived from methacryloyloxy-ethyl-trimethylammonium chloride [8], which claimed improved dyeability with different types of dyes. Most of these methods focused on the surface modification of meta-aramids, and few reported successes in dyeing paraaramids [9-11].

In terms of the dye characteristics suited for dyeing aramids, disperse dyes were developed to dye synthetic fibers and worked well on nylon [12], which were aliphatic or semi-aromatic polyamides, but limited success had been reported in dyeing aramids without harsh chemical treatments [4]. In solution dyeing, the pigments are added to the sulfuric acid solution just before spinning to achieve coloration of the resultant para-aramid fibers [13]. Further, disperse dyes are so-called because they tend to have low solubility in water and require special dispersing agents to effectuate coloration. Another type of dye, the cationic dyes, are exclusively used in solution dyeing, with the help of special dyeing auxiliaries and/or solvents in the case of meta-aramid fibers. In contrast, cationic dyes can dissociate into positively charged chromophore ions in aqueous solution and interact with the negative groups on the fiber molecules to form salts, which can become firmly attached to the fibers for dyeing. Using conventional dyeing methods to investigate dyeing characteristics of meta-aramid fibers with some commercial dyes, Kim and Choi [14] reported that the cationic dyes showed comparatively higher exhaustion yield comparing to those of disperse dyes and acid dyes, and under acidic conditions in the range of $\mathrm{pH} 3$ to 5 , the stability of cationic dyes could be enhanced, leading to higher adsorption.

We hypothesize that surface modification of para-aramids via nonthermal plasma (NTP) treatment, particularly an oxygen-containing plasma method, would introduce anionic dyeing sites on the surface to facilitate dyeing. Therefore, the objective of this study is to dye para-aramid textiles with a cationic dye using renewable materials and an environmentally friendly technology (NTP). Additionally, since the trend in the textile dyeing industry is to reduce or avoid the use and disposal of environmentally-unfriendly chemical additives [15], glycerol is used in this study as an alternative solvent to water or ethanol due to glycerol's non-toxicity, low volatility and high boiling point $\left(290^{\circ} \mathrm{C}\right)$, all of which make glycerol environmentally safe and suitable for use in the textile dyeing industry $[16,17]$. Further, glycerol is also used in this study, because there is a current worldwide effort to valorize the excessive amount of crude glycerol that has been generated as a result of massive biodiesel production [18-21].

Textile dyeing processes commonly add surfactants to the dyeing media, to ensure the uniform dispersion of dye in the media that promotes penetration of the dye into the fiber matrix [22]. Swelling agents or dyeing accelerators swell the fibers to facilitate the penetration of dye into the fibers. Swelling agents are particularly useful for increasing the dye substantivity in some instances with highly crystalline synthetic and blended fibers $[23,24]$. In this study, the nonionic surfactant and emulsifier Polysorbate 80 (TWEEN 80) and the swelling agent benzyl alcohol, both of which have been reported to have benefits in dyeing aramids $[25,26]$, were tested as additives to improve dyeing. 


\section{Materials and Methods}

\subsection{Materials}

The textiles tested in these experiments consisted of continuous filament 300 Denier para-aramid yarns in a tightly woven plain weave construction, as provided by the U.S. Army Combat Capabilities Development Command-Soldier Center (Natick, MA, USA). The cationic dye Basic Blue 11 (Victoria Blue R, CAS Number 2185-86-6) was purchased from Sigma-Aldrich (St. Louis, MO, USA); glycerol (99.5\% purity) and acetic acid (glacial) were purchased from Fisher Scientific (Waltham, MA, USA); Polysorbate 80 (TWEEN 80) and benzyl alcohol were purchased from Chem Center @ Amazon.com; and food grade refined soybean oil (100 g contains approximately $16 \mathrm{~g}$ of saturated fat, $23 \mathrm{~g}$ of monounsaturated fat, and $58 \mathrm{~g}$ of polyunsaturated fat) and laundry detergent (ECOS ${ }^{\circledR}$ Plus with Stain-Fighting Enzymes) were purchased from a local supermarket. All reagents and materials were used as-is without further purification.

\subsection{Experimental Methods}

The sequential experimentation methodology used in this study (Experiments A-F) was directed toward the goal of finding the combination of experimental factors that achieve the highest color strength of para-aramid fabrics dyed with a cationic dye. The experimental design used sequential factorial designs to quickly identify critical factors and conditions that improved dyeing. The factorial functions consisted of: (i) pretreatment with acetic acid, soybean oil and/or NTP treatment, (ii) dye solvent using water versus glycerol and (iii) the addition of the auxiliary additives of swelling agent and surfactant. The experimental design and subsequent analysis were carried out using specially designed software Design-Expert 6.0 (Stat-Ease, Inc., Minneapolis, MN, USA).

\subsection{Pretreatment (Acetic Acid, Soybean Oil, NTP)}

Para-aramid textile fabric samples $\left(\sim 645 \mathrm{~mm}^{2}\right.$ or $\left.\sim 1 \mathrm{in}^{2}\right)$ were pretreated by simply immersing the fabric samples into a Petri dish containing either $20 \mathrm{wt}$ \% aqueous acetic acid solution or soybean oil, according to an experimental design. The samples were removed after $15 \mathrm{~h}$, transferred onto a paper towel and hand-pressed with a roller to force out any excess liquid.

For fabric samples subjected to NTP exposure, the NTP treatment was carried out using an in-house made Surface Dielectric Barrier Discharge (SDBD) system. The SDBD method was chosen because it generates a higher density of micro-discharges that are limited to the sample surface compared to the Volume Dielectric Barrier Discharge (VDBD) method. The SDBD therefore avoids the formation of pinholes in the para-aramid fabric samples, which is commonly associated with VDBD and caused by hot electron bombardment of the para-aramid fabrics. Teflon-coated aramids have been made wettable after a $30 \mathrm{~s}$ exposure to this SDBD.

The SDBD system has been described previously for dyeing with a disperse dye [27] and is summarized here. The SDBD apparatus uses ambient air as the feed gas and comprises two electrodes that are separated by an alumina dielectric plate (dimensions = $108 \times 95 \times 1 \mathrm{~mm}^{3}$ thick) and powered by a high voltage power source with a sinusoidal high voltage of $9.2 \mathrm{kV}$ that was tuned to a $23.2 \mathrm{kHz}$ resonance frequency (see Figure 1). Embedded at the top of the alumina plate was an induction electrode made of rectangular copper tape, and at the bottom of the alumina plate was a discharge electrode (17 tungsten strips interconnected). Fabric samples were placed on the rotating stage and the SDBD plate was lowered to a height $1 \mathrm{~mm}$ above the sample. When the power was switched on, the plasma emissions, which included reactive oxygen and nitrogen species (RONS) and other high-energy radicals, interacted with the fabric samples (typically for 1-2.5 min). Then, the power was turned off and the sample was removed for dyeing. 


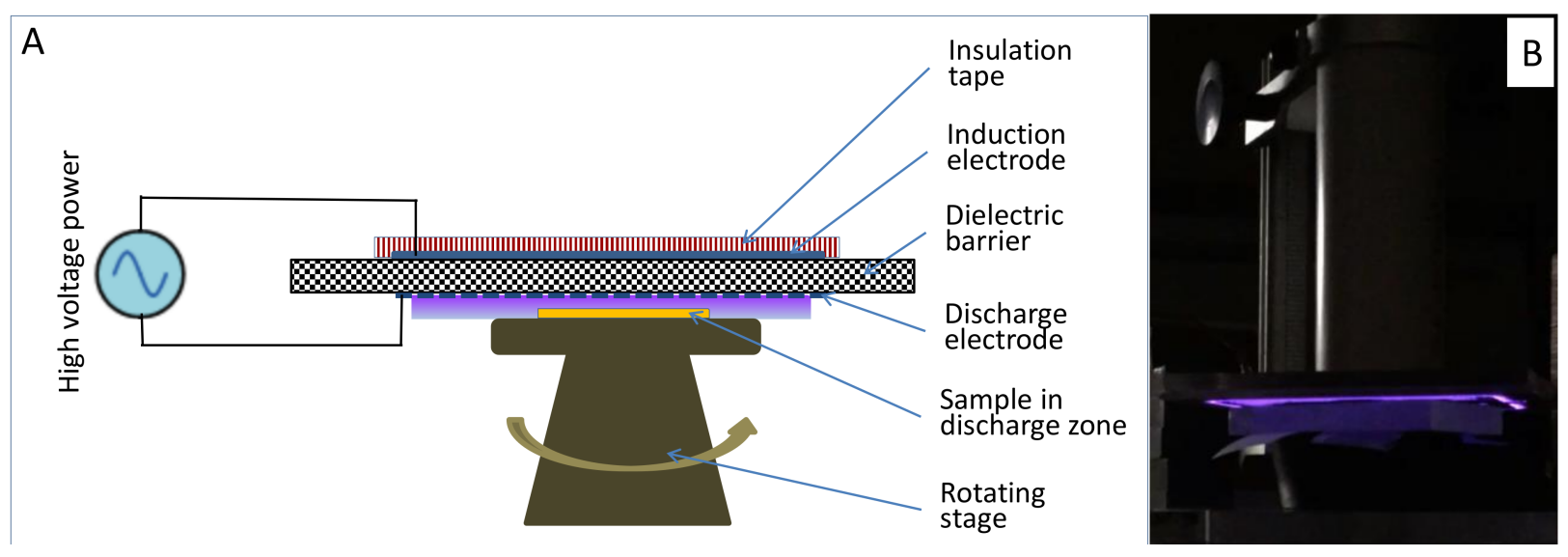

Figure 1. (A) Diagram of the NTP system and (B) photo showing a sample under glowing plasma discharge.

\subsection{Dyeing Experimental Procedures}

The cationic dye Victoria Blue $\mathrm{R}$ is soluble in water and in glycerol, so distilled water, glycerol and aqueous glycerol solutions were tested and compared as the dye solvent. The aqueous glycerol solutions are expressed as their volumetric percent of glycerol. The dye solvents were moderately heated $\left(\mathrm{T} \approx 50^{\circ} \mathrm{C}\right)$ with vigorous stirring using a magnetic stirrer, and appropriate amounts of Victoria Blue R dye, acetic acid, surfactant and swelling agent were added to the respective solvents in accordance with the design of the experiment. The dye bath liquid was dispensed into separate vials that were simultaneously heated and stirred on a Reacti-Therm system (ThermoFisher Scientific, Waltham, MA, USA). Fabric samples were loaded into the vials for dyeing. The dye bath and fabric samples took about $30 \mathrm{~min}$ to reach a designated temperature, held at the temperature for $1 \mathrm{~h}$, then cooled for 20 min with the Reacti-Therm system shut off. After the dyeing, samples were rinsed in flowing warm tap water for $2 \mathrm{~min}$, rinsed in cold water for $2 \mathrm{~min}$, then dried in a programmable convective oven at $\mathrm{T}=150{ }^{\circ} \mathrm{C}$ for $2 \mathrm{~min}$ (after starting at $\mathrm{T}=30^{\circ} \mathrm{C}$ and increasing the temperature at a rate of $30^{\circ} \mathrm{C} / \mathrm{min}$ ) to fix the dye.

\subsection{Color Strength Analysis}

Prior to determining the color strength, the fabric samples were washed with laundry detergent using a homemade tumbler, in accordance with the ISO standard 105-C10:2006 protocol [28], then rinsed and dried as described in Section 2.4 above.

Estimates of the color strength for each of the dyed fabric samples were determined at the wavelength of maximum absorbance for Victoria Blue $R$ dye $\left(\lambda_{\max }=615 \mathrm{~nm}\right)$ by measuring percent spectral reflectance (\%R) in the visible range with a SPECTRO 1 spectrophotometer (Variable Inc., Chattanooga, TN, USA). Results were expressed as the samples' absorption (K) and scattering (S) characteristics as its K/S value, which varies approximately linearly with colorant concentration, according to the Kubelka-Monk equation (Equation (1)) [29].

$$
K / S=\frac{(1-0.01 R)^{2}}{2(0.01 R)}
$$

\subsection{FTIR Analysis}

In order to monitor some of the chemical changes occurring during the pretreatment and dyeing processes, Attenuated Total Reflection-Fourier Transform Infrared (ATR-FTIR) spectroscopy was used to analyze the fabric samples at different stages of the pretreatment and dyeing processes with the Victoria Blue R dye. In summary, fabric samples were placed on a potassium bromide $(\mathrm{KBr})$ plate, pressed under the germanium crystal of ATR (UMA 400, Varian Inc., Palo Alto, CA, USA) and scanned in the mid-IR region $\left(500-4000 \mathrm{~cm}^{-1}\right.$ with a $4 \mathrm{~cm}^{-1}$ resolution) with an FTIR spectrometer (Excalibur 3100, Varian Inc., Palo Alto, 
CA, USA) equipped with an Attenuated Total Reflection (ATR) accessory. The ATR-FTIR spectra were displayed in absorbance units with each spectrum representing an average of 128 scans and taking into account the background spectrum acquired using a blank KBr plate.

\section{Results and Discussion}

\subsection{Experiments A-F: Analysis}

Experiment A was a 4-factor, 2-level, full factorial experiment designed to probe the effects of dye solvent (water or glycerol), pretreatment with acetic acid and/or NTP treatment for $60 \mathrm{sec}$ and the addition of the swelling agent benzyl alcohol. The dyeing results are also shown in Table 1.

Table 1. Experiment A: experimental design and results ${ }^{\circledR}$.

\begin{tabular}{ccccccc}
\hline Sample & $\begin{array}{c}\text { Dye } \\
\text { Solvent }\end{array}$ & Pretreatment & NTP Time (s) & Swelling Agent & K/S & $\begin{array}{c}\text { K/S } \\
\text { Std * }\end{array}$ \\
\hline A1 & Water & None & 60 & None & 1.26 & 0.009 \\
A2 & Water & None & 0 & None & 1.20 & 0.054 \\
A3 & Water & Acetic acid & 60 & None & 1.22 & 0.011 \\
A4 & Water & Acetic acid & 0 & None & 1.12 & 0.018 \\
A5 & Water & None & 60 & Benzyl-OH & 1.44 & 0.003 \\
A6 & Water & None & 0 & Benzyl-OH & 1.56 & 0.026 \\
A7 & Water & Acetic acid & 60 & Benzyl-OH & 1.74 & 0.021 \\
A8 & Water & Acetic acid & 0 & Benzyl-OH & 1.59 & 0.016 \\
A9 & Glycerol & None & 60 & None & 0.42 & 0.005 \\
A10 & Glycerol & None & 0 & None & 0.39 & 0.009 \\
A11 & Glycerol & Acetic acid & 60 & None & 0.45 & 0.004 \\
A12 & Glycerol & Acetic acid & 0 & None & 0.40 & 0.005 \\
A13 & Glycerol & None & 60 & Benzyl-OH & 0.41 & 0.002 \\
A14 & Glycerol & None & 0 & Benzyl-OH & 0.42 & 0.003 \\
A15 & Glycerol & Acetic acid & 60 & Benzyl-OH & 0.48 & 0.019 \\
A16 & Glycerol & Acetic acid & 0 & Benzyl-OH & 0.47 & 0.004 \\
\hline
\end{tabular}

${ }^{\circ}$ Experiment conducted at soaking time in $20 \mathrm{wt} . \%$ acetic acid solution $=15 \mathrm{~h}$, dye concentration $=0.1 \mathrm{wt} . \%$, Benzyl alcohol concentration $=2 \mathrm{wt.} \%, \mathrm{~T}=140^{\circ} \mathrm{C}$, dyeing time $=1 \mathrm{~h} .{ }^{*}$ Values represent mean and standard error of 3 replicates.

Overall, the highest K/S value achieved in Experiment A is only 1.74 (sample A7) through the combination of water as solvent, pretreatments with acetic acid and NTP (60 s) and the addition of swelling agent benzyl alcohol. The Analysis of Variance (ANOVA) factorial model terms were selected based on the half-normal probability plot, which indicated that all the factors and some of their interactions were significant ( $t$-tests for coefficients, $p<0.02)$. Since all of the factors are involved in interactions, statistical interpretations of only the significant interaction terms are shown in Figure 2.

Evidently in Figure 2, the dye solvent had the most significant influence on the color strength (K/S value), with water performing significantly better than glycerol. Adding benzyl alcohol to the dye bath increased the color strength, and the effect of benzyl alcohol was slightly enhanced by the acetic acid pretreatment with water as the dye solvent. The effects of pretreatment with acetic acid and NTP were not obvious, slightly improving the color strength with their synergy.

A significant loss of water was observed in the dye bath during Experiment A due to the evaporation of water at the dyeing temperature $\mathrm{T}=140{ }^{\circ} \mathrm{C}$. The use of glycerol as the dye solvent effectuated dyeing at $\mathrm{T}=140{ }^{\circ} \mathrm{C}$ without the concomitant evaporative loss of solvent from the dye bath but reached significantly lower values of color strengths. The cationic dye might not be well-dissociated in glycerol as the solvent, and the high viscosity of pure glycerol compared to water and the occurrence of hydrogen bonding between the 
dye and glycerol might hinder the mobility of the cationic dye and retard its diffusion onto the para-aramids.
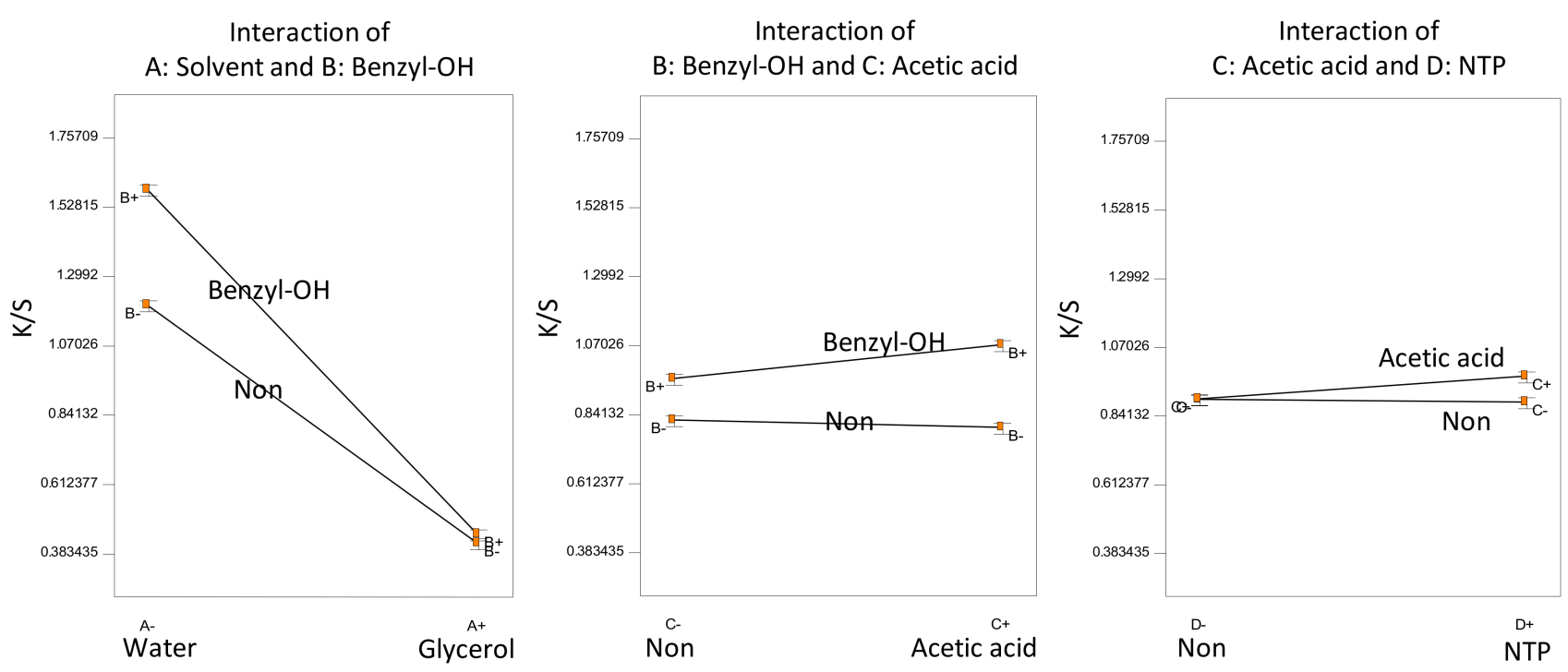

Figure 2. Statistical inference of Experiment A: significant factorial interactions.

To overcome the drawbacks of using glycerol as the dye solvent, full factorial Experiment B was designed using $50 \%$ or $80 \%$ aqueous glycerol solutions as the dye solvent. Additional factors were investigated and included a pretreatment of soaking the paraaramid fabrics in soybean oil and/or applying further treatment with NTP and adding benzyl alcohol as the swelling agent. Table 2 lists the detailed experimental design and resultant $\mathrm{K} / \mathrm{S}$ values. Even though using $50 \%$ or $80 \%$ aqueous glycerol solutions as the dye solvent suppressed the loss of the dye bath solution, the highest $\mathrm{K} / \mathrm{S}$ value achieved in this experiment was only 0.94 (sample B11) with 50\% aqueous glycerol solution as the solvent and soybean oil and NTP (60 s) as the pretreatment.

Table 2. Experiment B: experimental design and results ${ }^{\circledR}$.

\begin{tabular}{ccccccc}
\hline Sample & Dye Solvent & Pretreatment & $\begin{array}{c}\text { Swelling } \\
\text { Agent }\end{array}$ & $\begin{array}{c}\text { NTP } \\
\text { Time (s) }\end{array}$ & K/S & $\begin{array}{c}\text { K/S } \\
\text { Std * }\end{array}$ \\
\hline B1 & $80 \%$ Glycerol & Soy oil & Benzyl-OH & 60 & 0.70 & 0.015 \\
B2 & $80 \%$ Glycerol & Soy oil & Benzyl-OH & 0 & 0.57 & 0.012 \\
B3 & $80 \%$ Glycerol & Soy oil & None & 60 & 0.79 & 0.014 \\
B4 & $80 \%$ Glycerol & Soy oil & None & 0 & 0.56 & 0.004 \\
B5 & $80 \%$ Glycerol & None & Benzyl-OH & 60 & 0.55 & 0.003 \\
B6 & $80 \%$ Glycerol & None & Benzyl-OH & 0 & 0.53 & 0.004 \\
B7 & $80 \%$ Glycerol & None & None & 60 & 0.46 & 0.017 \\
B8 & $80 \%$ Glycerol & None & None & 0 & 0.44 & 0.013 \\
B9 & $50 \%$ Glycerol & Soy oil & Benzyl-OH & 60 & 0.84 & 0.005 \\
B10 & $50 \%$ Glycerol & Soy oil & Benzyl-OH & 0 & 0.67 & 0.009 \\
B11 & $50 \%$ Glycerol & Soy oil & None & 60 & 0.94 & 0.001 \\
B12 & $50 \%$ Glycerol & Soy oil & None & 0 & 0.92 & 0.005 \\
B13 & $50 \%$ Glycerol & None & Benzyl-OH & 60 & 0.81 & 0.014 \\
B14 & $50 \%$ Glycerol & None & Benzyl-OH & 0 & 0.70 & 0.010 \\
B15 & $50 \%$ Glycerol & None & None & 60 & 0.72 & 0.006 \\
B16 & $50 \%$ Glycerol & None & None & 0 & 0.82 & 0.013 \\
\hline
\end{tabular}

$\bar{\Theta}$ Experiment carried out with soaking in soybean oil time $=15 \mathrm{~h}$, dye concentration $=0.1 \mathrm{wt} . \%$, Benzyl alcohol concentration $=2 \mathrm{wt} . \%, \mathrm{~T}=140{ }^{\circ} \mathrm{C}$ and dyeing time $=1 \mathrm{~h} .{ }^{*}$ Mean and standard error of 3 replicates. 
The analysis of variance (ANOVA) of this factorial design indicates that the main effect of all the factors and some of their interactions are significant $(p<0.005)$. The half-normal probability plot was used to select the ANOVA model terms, and only the significant interaction terms of the model are presented in Figure 3.
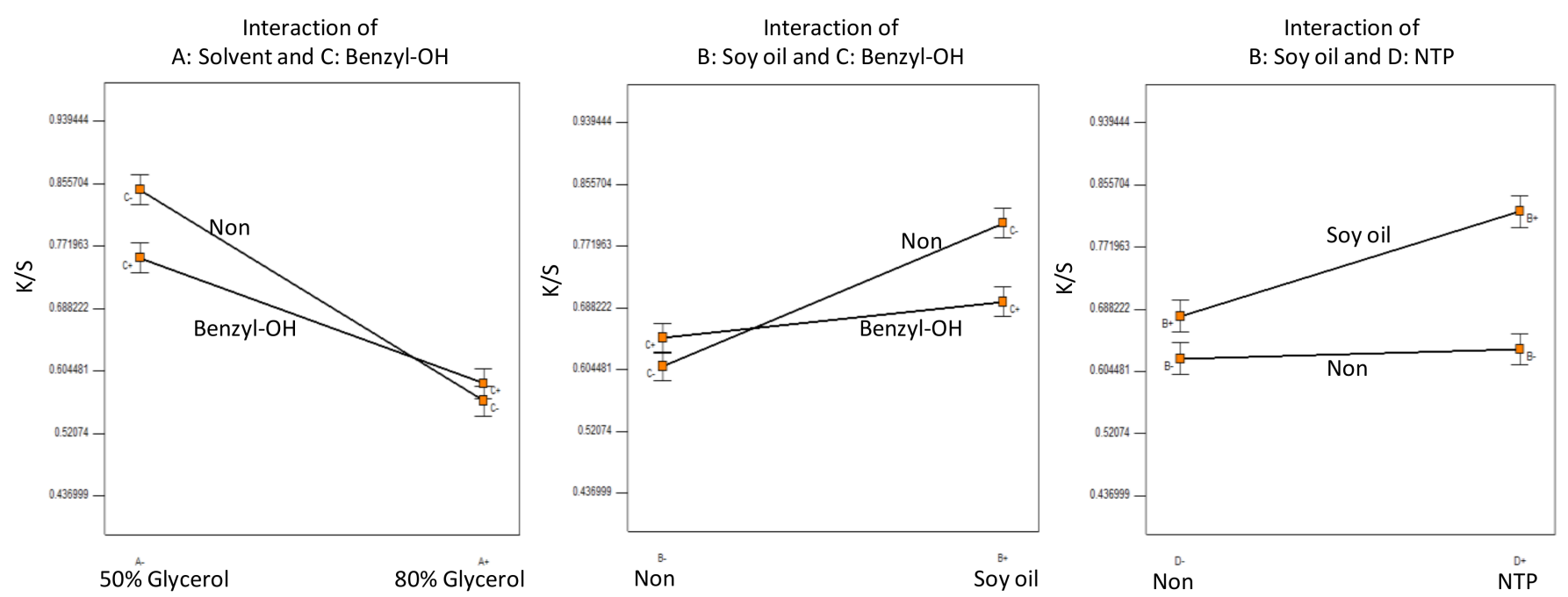

Figure 3. Statistical inference of Experiment B: significant factorial interactions.

The $50 \%$ aqueous glycerol solution performed better than the $80 \%$ aqueous glycerol solution as the dye solvent (Figure 3). Benzyl alcohol appeared to be incompatible with aqueous glycerol or soybean oil, which might hinder its diffusion and swelling functions and consequently limited the benefits of soybean oil on dyeing. Soaking the para-aramids in soybean oil slightly improved the dyeing color strength, while soaking the para-aramids in soybean oil with subsequent NTP treatment for $60 \mathrm{~s}$ increased the color strength significantly. Without a pretreatment of soybean oil pretreatment, NTP had negligible effect on the dyeing strength.

The full factorial design for Experiment $C$ used a lower dyeing temperature $\left(\mathrm{T}=90{ }^{\circ} \mathrm{C}\right)$, compared $50 \%$ aqueous glycerol solution with water as the dye solvent and used soybean oil pretreatments and NTP treatment times of $90 \mathrm{~s}$. The experimental design and dyeing results are compiled in Table 3 . The highest $\mathrm{K} / \mathrm{S}$ value achieved in this experiment is 1.72 (sample C11), which is higher than the highest value obtained in Experiment B (0.94). Experiment B was carried out at a higher temperature $\left(\mathrm{T}=140{ }^{\circ} \mathrm{C}\right.$ vs. $\mathrm{T}=90{ }^{\circ} \mathrm{C}$ for Experiment C), used soybean oil with a shorter NTP treatment time (60 s vs. $90 \mathrm{~s}$ for Experiment C) and used $50 \%$ or $80 \%$ aqueous glycerol solutions as the dye solvent (vs. water or $50 \%$ aqueous glycerol in Experiment C).

The half-normal probability plot was used to select the ANOVA model terms and resulted in a significant model (F-test, $p<0.0001$ ). All of the terms included in the model were significant ( $t$-tests, $p<0.007)$, except for the main effect of swelling agent ( $t$-test, $p=0.59$ ). Since all of the factors were involved in interactions, only the significant interaction terms are interpreted in Figure 4. 
Table 3. Experiment C: experimental design and the results ${ }^{\circledR}$.

\begin{tabular}{ccccccc}
\hline Sample & Dye Solvent & Pretreatment & $\begin{array}{c}\text { Swelling } \\
\text { Agent }\end{array}$ & $\begin{array}{c}\text { NTP } \\
\text { Time (s) }\end{array}$ & K/S & $\begin{array}{c}\text { K/S } \\
\text { Std * }\end{array}$ \\
\hline C1 & $50 \%$ Glycerol & Soy oil & Benzyl-OH & 90 & 0.91 & 0.021 \\
C2 & $50 \%$ Glycerol & Soy oil & Benzyl-OH & 0 & 0.60 & 0.002 \\
C3 & $50 \%$ Glycerol & Soy oil & None & 90 & 1.06 & 0.045 \\
C4 & $50 \%$ Glycerol & Soy oil & None & 0 & 0.57 & 0.006 \\
C5 & $50 \%$ Glycerol & None & Benzyl-OH & 90 & 0.96 & 0.009 \\
C6 & $50 \%$ Glycerol & None & Benzyl-OH & 0 & 0.74 & 0.015 \\
C7 & $50 \%$ Glycerol & None & None & 90 & 1.04 & 0.027 \\
C8 & $50 \%$ Glycerol & None & None & 0 & 0.66 & 0.013 \\
C9 & Water & Soy oil & Benzyl-OH & 90 & 1.66 & 0.262 \\
C10 & Water & Soy oil & Benzyl-OH & 0 & 1.15 & 0.008 \\
C11 & Water & Soy oil & None & 90 & 1.72 & 0.072 \\
C12 & Water & Soy oil & None & 0 & 0.86 & 0.008 \\
C13 & Water & None & Benzyl-OH & 90 & 1.68 & 0.024 \\
C14 & Water & None & Benzyl-OH & 0 & 1.31 & 0.104 \\
C15 & Water & None & None & 90 & 1.09 & 0.034 \\
C16 & Water & None & None & 0 & 0.92 & 0.012 \\
\hline
\end{tabular}

@ Experiment was carried out with soaking in soybean oil for time $=15 \mathrm{~h}$, dye concentration $=0.1 \mathrm{wt} . \%$, Benzyl alcohol concentration $=2 \mathrm{wt} . \%, \mathrm{~T}=90^{\circ} \mathrm{C}$ and dyeing time $=1 \mathrm{~h}$. ${ }^{*}$ Mean and standard error of 3 replicates.
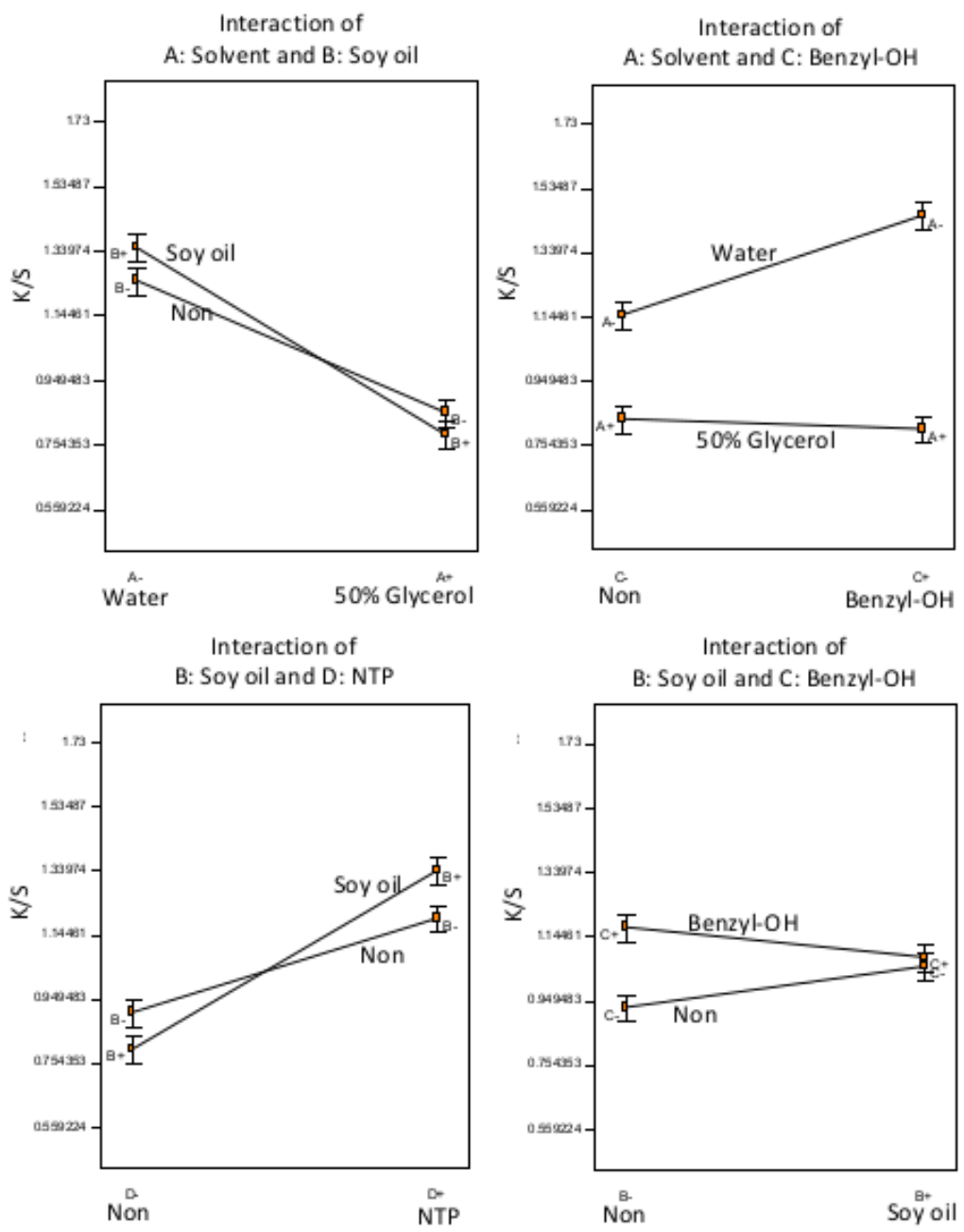

Figure 4. Statistical inference of Experiment C: significant factorial interactions. 
According to the half-normal probability plot, the solvent had the most influence on color strength among all of the factors, with water as the solvent performing significantly better than the $50 \%$ aqueous glycerol solution. Soybean oil pretreatment followed by NTP significantly improved the color strength, although NTP treatment without the soybean oil pretreatment also improved the color strength, but to a lesser degree. Benzyl alcohol performed better in water than in 50\% aqueous glycerol solution as the solvent, another indication that the benzyl alcohol was not compatible with glycerol in Experiment B. Further, the effect of benzyl alcohol was minimal on the samples pretreated with soybean oil, but benzyl alcohol significantly improved dyeing without the soybean oil pretreatment, also indicating that benzyl alcohol was not compatible with soybean oil. Without a subsequent NTP treatment, soybean oil soaking resulted in slightly lower color strength, which seems contradictory to the results in Experiment B. However, Experiment $C$ was carried out at a much lower temperature $\left(\mathrm{T}=90^{\circ} \mathrm{C}\right.$ vs. $\mathrm{T}=140{ }^{\circ} \mathrm{C}$ in experiment $\mathrm{B}$ with water or $50 \%$ aqueous glycerol solution (vs. $50 \%$ or $80 \%$ aqueous glycerol in Experiment B in the dye bath, and these factors may have limited the beneficial effects of the soybean oil in achieving dyeing without an NTP treatment. The longer NTP treatment time in Experiment C $(90 \mathrm{~s}$ vs. $60 \mathrm{~s}$ in Experiment B also significantly improved dyeing even without the soaking in soybean oil pretreatment.

From the results of the previous Experiments A-C, it is clear that the use of glycerol in the dye solvent does not help with dyeing, and there is a potential for improving dyeing using a pretreatment consisting of soaking in soybean oil followed by NTP. Accordingly, Experiment D used a lower dyeing temperature $\left(T=90^{\circ} \mathrm{C}\right)$, water as the dye solvent, a wider range of NTP treatment times $(t=30-150 \mathrm{~s})$, eliminated the swelling agent benzyl alcohol as a factor and added surfactant as a new factor using TWEEN 80, because of its reported benefit in dyeing aramids $[25,26]$. Results of the 3-factor 2-level full factorial design are presented in Table 4.

Table 4. Experiment D: experimental design and the results ${ }^{\circledR}$.

\begin{tabular}{cccccc}
\hline Sample & Surfactant & Pretreatment & NTP Time (s) & K/S & K/S Std \\
\hline D1 & None & None & 30 & 0.81 & 0.006 \\
D2 & None & Soy oil & 30 & 1.01 & 0.008 \\
D3 & None & None & 150 & 0.97 & 0.008 \\
D4 & None & Soy oil & 150 & 1.20 & 0.017 \\
D5 & TWEEN & None & 30 & 0.61 & 0.010 \\
D6 & TWEEN & Soy oil & 30 & 0.60 & 0.002 \\
D7 & TWEEN & None & 150 & 0.79 & 0.003 \\
D8 & TWEEN & Soy oil & 150 & 0.84 & 0.005 \\
\hline
\end{tabular}

${ }^{\circledR}$ Experiment carried out with soaking in soybean oil for time $=15 \mathrm{~h}$, dye solvent $=$ water, dye concentration $=0.1$ wt. $\%, \mathrm{~T}=90^{\circ} \mathrm{C}$ and dyeing time $=1 \mathrm{~h} .{ }^{*}$ Mean and standard error of 3 replicates.

ANOVA for the factorial design indicated a significant model ( $F$-test, $p<0.0001)$. All three of the factors and their two-way interactions were significant $(t$-test, $p<0.0002)$. Since all of the factors are involved in interactions, only the interaction plots are shown in Figure 5.

According to the half-normal probability plot, the surfactant TWEEN 80 had the highest impact on the dyeing color strength, followed by NTP treatment time, then soybean oil pretreatment in descending order. The use of TWEEN 80 resulted in weaker color strength (Figure 5). The surfactant, although helping to form a dye dispersion, might also hinder the diffusion of the dye onto the para-aramid fiber fabrics, even in the presence of soybean oil. The soybean oil pretreatment improved dyeing, which was further improved by longer subsequent NTP treatment times. Evidently, the longer NTP treatment time of $150 \mathrm{~s}$, comparing to the treatment time of $30 \mathrm{~s}$, resulted in higher color strength in the presence or the absence of TWEEN 80 surfactant. 

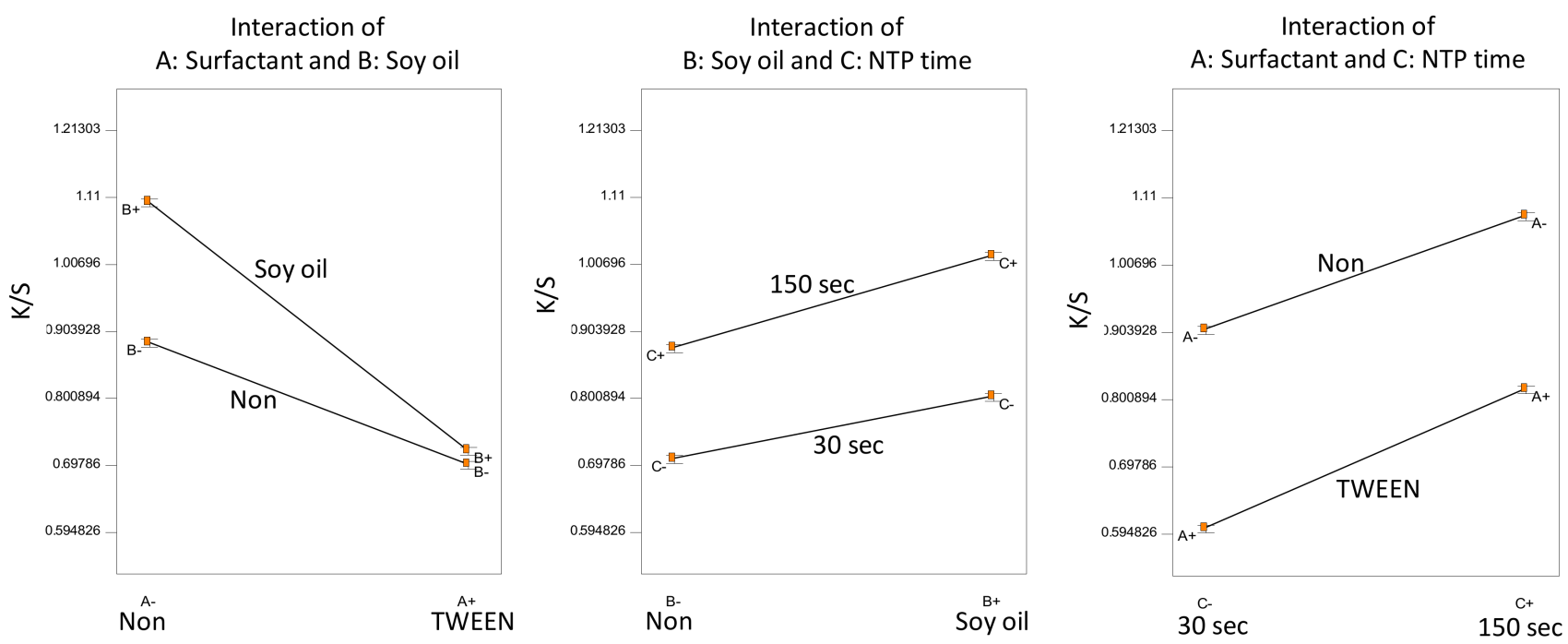

Figure 5. Statistical inference of Experiment D: significant factorial interactions.

It appeared that the NTP treatment time is crucial to the dyed color strength, especially for the soybean oil pretreated samples. Therefore, Experiment $\mathrm{E}$ was designed to optimize the NTP treatment time. In Experiment E, samples were soaked in soybean oil for $15 \mathrm{~h}$, water was used as the dye solvent with a $0.1 \mathrm{wt} . \%$ dye concentration and with no other additives and the dyeing temperature was $\mathrm{T}=90^{\circ} \mathrm{C}$ for $1 \mathrm{~h}$.

Results of the one-factor factorial design with NTP treatment time varied from 0-150 s are presented in Figure 6. The effects of NTP treatment at these experimental conditions show (Figure 6) that an NTP treatment time of 120 s provided the optimal result in dyeing the soybean oil pretreated samples in terms of color strength as represented by K/S values. NTP treatment times shorter than $120 \mathrm{~s}$ achieved dyeing, but to a lesser extent and NTP treatment times longer than $120 \mathrm{~s}$ decreased the $\mathrm{K} / \mathrm{S}$ value, probably due to the degradation of the soybean oil network by the increased exposure to the NTP treatment.

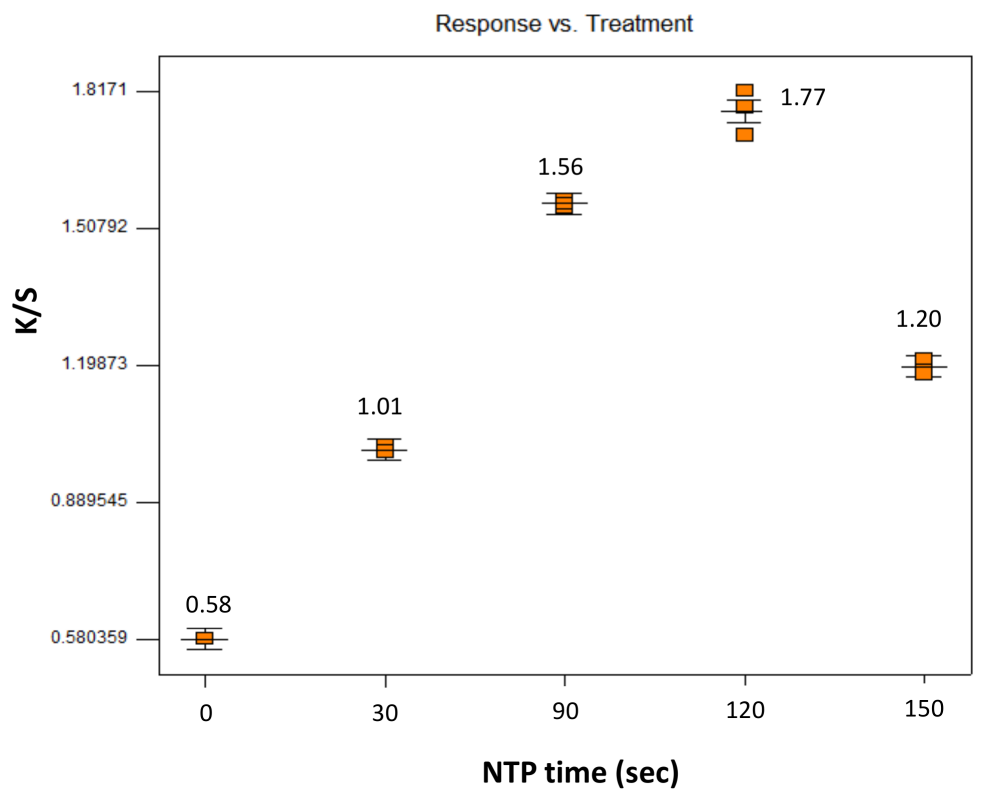

Figure 6. Effect of NTP time on K/S value of soybean oil-soaked para-aramids.

Based on the results of Experiments A-E, Experiment $\mathrm{F}$ was designed to optimize dyeing performance by developing a suitable recipe that included auxiliary additives 
(swelling agent and acetic acid) in the dye bath and a suitable dyeing process that in terms of the dyeing temperature $\left(\mathrm{T}=70^{\circ} \mathrm{C}\right.$ or $\left.100^{\circ} \mathrm{C}\right)$ and the effects of a $120 \mathrm{~s}$ NTP treatment prior to versus post soaking in soybean oil. The addition of acetic acid into the dye bath brought down the $\mathrm{pH}$ to about 3 , which should make the conditions favorable for cationic dyes [14]. Results of the 4-factor full factorial design are shown in Table 5.

Table 5. Experiment F: experimental design and the results ${ }^{\circledR}$.

\begin{tabular}{|c|c|c|c|c|c|c|c|}
\hline Sample & Temperature & Acetic Acid & $\begin{array}{c}\text { Swelling } \\
\text { Agent }\end{array}$ & NTP & $\mathrm{K} / \mathrm{S}$ & $\begin{array}{c}\mathrm{K} / \mathrm{S} \\
\text { Std }\end{array}$ & $\Delta \mathrm{K} / \mathbf{S}^{\#}$ \\
\hline $\mathrm{F} 1$ & $70{ }^{\circ} \mathrm{C}$ & Yes & Benzyl-OH & Post & 1.08 & 0.016 & -0.08 \\
\hline $\mathrm{F} 2$ & $70{ }^{\circ} \mathrm{C}$ & Yes & Benzyl-OH & Prior & 0.91 & 0.022 & -0.13 \\
\hline F3 & $70{ }^{\circ} \mathrm{C}$ & Yes & None & Post & 0.99 & 0.005 & -0.17 \\
\hline F4 & $70{ }^{\circ} \mathrm{C}$ & Yes & None & Prior & 0.91 & 0.045 & -0.27 \\
\hline F5 & $70{ }^{\circ} \mathrm{C}$ & No & Benzyl-OH & Post & 1.18 & 0.008 & -0.15 \\
\hline F6 & $70{ }^{\circ} \mathrm{C}$ & No & Benzyl-OH & Prior & 1.12 & 0.025 & -0.27 \\
\hline F7 & $70{ }^{\circ} \mathrm{C}$ & No & None & Post & 0.96 & 0.023 & -0.06 \\
\hline F8 & $70{ }^{\circ} \mathrm{C}$ & No & None & Prior & 0.93 & 0.007 & -0.31 \\
\hline F9 & $100^{\circ} \mathrm{C}$ & Yes & Benzyl-OH & Post & 1.55 & 0.012 & -0.04 \\
\hline F10 & $100^{\circ} \mathrm{C}$ & Yes & Benzyl-OH & Prior & 1.15 & 0.016 & -0.20 \\
\hline F11 & $100^{\circ} \mathrm{C}$ & Yes & None & Post & 1.30 & 0.007 & -0.10 \\
\hline F12 & $100^{\circ} \mathrm{C}$ & Yes & None & Prior & 1.06 & 0.020 & -0.17 \\
\hline F13 & $100^{\circ} \mathrm{C}$ & No & Benzyl-OH & Post & 1.45 & 0.010 & -0.12 \\
\hline F14 & $100^{\circ} \mathrm{C}$ & No & Benzyl-OH & Prior & 1.21 & 0.068 & -0.16 \\
\hline F15 & $100^{\circ} \mathrm{C}$ & No & None & Post & 2.28 & 0.064 & -0.09 \\
\hline F16 & $100^{\circ} \mathrm{C}$ & No & None & Prior & 1.01 & 0.013 & -0.17 \\
\hline
\end{tabular}

${ }^{\circledR}$ Experiment carried out with soaking in soybean oil for time $=15 \mathrm{~h}$, dye solvent $=$ water, dye concentration $=$ $0.1 \mathrm{wt} . \%$, dyeing time $=1 \mathrm{~h}$, Additive concentrations $=1 \mathrm{wt} . \%$ Acetic acid and $/$ or $2 \mathrm{wt} . \%$ Benzyl alcohol and the NTP treatment time $=120 \mathrm{~s}$ prior to or post soaking in soybean oil for $15 \mathrm{~h}$. * Mean and standard error of 3 replicates. " The change in $\mathrm{K} / \mathrm{S}$ value was calculated by subtracting the K/S after the 1 st detergent wash from the K/S value measured after the 2 nd detergent wash.

The half-normal probability plot indicated that impact of the factors is in the order of Dye temperature $>$ NTP $>$ Acetic acid. Even though the overall ANOVA model was significant $(p<0.0001)$, the coefficient for benzyl alcohol was not significant $(t$-test, $p=0.63)$. The only significant interaction term is Temperature $\times$ NTP ( $t$-test, $p=0.0003$ ), while the Temperature $\times$ Benzyl-OH (Benzyl alcohol) interaction was marginally significant ( $t$-test, $p=0.085)$. Figure 7 plots out the main effects of all the factors along with the two interactions.

Acetic acid was the only factor not involved in any significant interactions (Figure 7A). The addition of $1 \mathrm{wt} . \%$ acetic acid in the dye bath slightly decreased the dyeing color strength. All of the other three factors were involved in the two interactions, so their effects are discussed in the context of their interactions (Figure 7B).

The dyeing temperature and NTP after soaking in soybean oil significantly impacted the dyeing results, whereas the use of benzyl alcohol did not significantly influence the dyeing color strength. In Experiment $\mathrm{F}$, the largest $\mathrm{K} / \mathrm{S}$ value achieved was $\mathrm{K} / \mathrm{S}=2.28$ (sample F15) in dyeing conditions with $\mathrm{T}=100{ }^{\circ} \mathrm{C}$ in a water-based dye bath, with a pretreatment of soaking in soybean oil followed by a $120 \mathrm{~s}$ NTP treatment and no other additives of benzyl alcohol or acetic acid in the dye bath. It is noteworthy that $\mathrm{T}=100{ }^{\circ} \mathrm{C}$ is the highest temperature that can be used for the water-based dye bath at atmospheric pressure without significant loss of water due to evaporation. In general, dyeing at $\mathrm{T}=100{ }^{\circ} \mathrm{C}$ was better than dyeing at $\mathrm{T}=70{ }^{\circ} \mathrm{C}$. While NTP treatment $(120 \mathrm{~s})$ prior to soaking in soybean oil did not show a significant effect on dyeing, NTP treatment after soaking in soybean oil significantly improved the color strength, especially when the dyeing was carried out in the higher temperature regime of $\mathrm{T}=100^{\circ} \mathrm{C}$. This clearly points out that the improved dyeing effect should be attributed to the chemical reactions between soybean oil and NTP. 
A
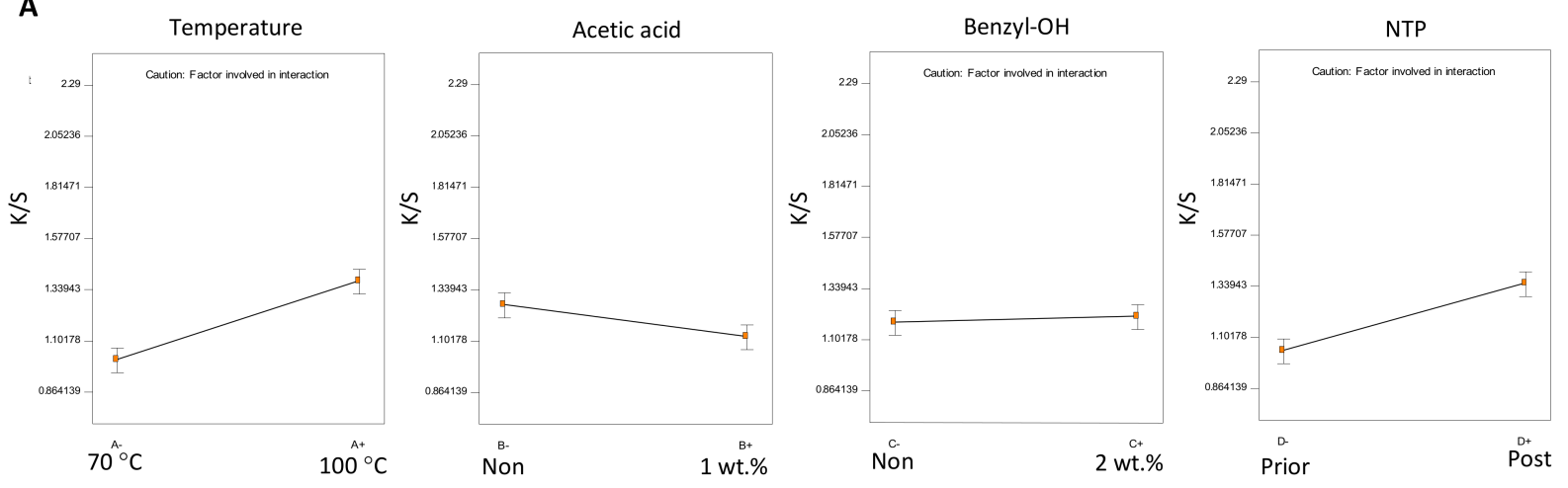

B
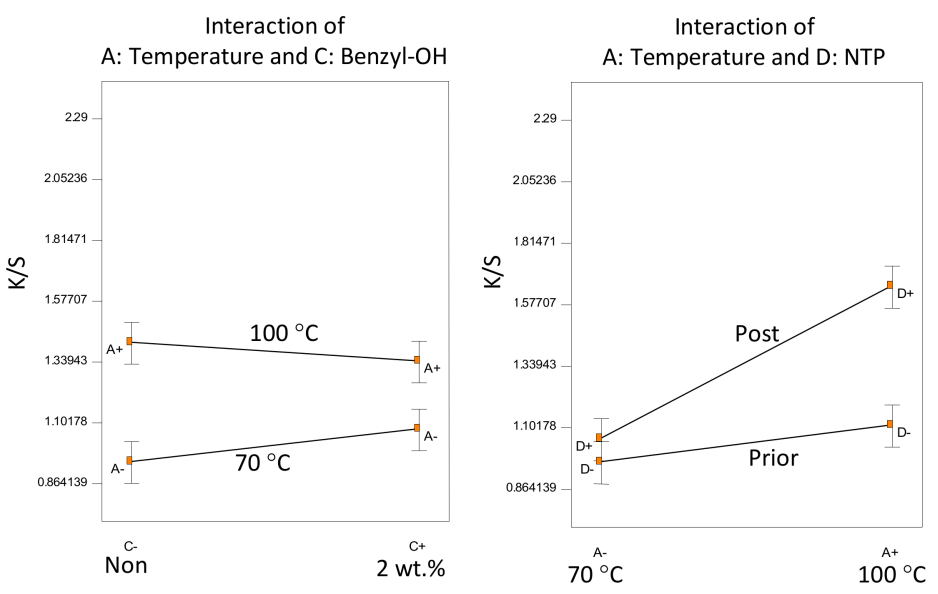

Figure 7. Analysis of Experiment F. (A) Main effects of all of the factors and (B) the significant interactions.

All samples were laundered with a detergent wash for a second time according to the same protocol described in Section 2.5, to determine colorfastness in terms of the change in $\mathrm{K} / \mathrm{S}$ values (denoted as $\Delta \mathrm{K} / \mathrm{S}$ in Table 5). A negative sign of the $\Delta \mathrm{K} / \mathrm{S}$ value indicates a decrease in $\mathrm{K} / \mathrm{S}$ value after the second wash with detergent. Generally, higher temperature and NTP treatment after soaking in soybean oil resulted in better dyeing strength and more durable dyeing (colorfastness) after laundering.

For the purposes of providing a visual demonstration comparing the dyeing strengths of different treatments, select samples were imaged using a flatbed scanner (Figure 8). Compared with the previous investigation of dyeing para-aramids with this method and using a disperse dye [27], it is demonstrated that the pretreatment of soybean oil followed by NTP treatment method is compatible with dyeing with both disperse dye and cationic dye. Further, this method enables dyeing to a significantly high color strength, although the disperse dye requires glycerol as a dispersant, but water as the solvent is better suited for the use of cationic dye. Taken together, these results demonstrate the potential for this method to replace hazardous chemicals currently used in dyeing practices with renewable materials and environmentally friendly ("green") technologies, to improve the dyeing of para-aramid textiles.

\subsection{FTIR Analysis}

As shown in Figure 9, the following characteristic peaks of soybean oil (line I) are well represented: $3009 \mathrm{~cm}^{-1}(=\mathrm{C}-\mathrm{H}$ stretching of aliphatic alkenes) in unsaturated fatty acids, $2922 \mathrm{~cm}^{-1}$ (- $\mathrm{CH}_{2}$ asymmetric stretching), $2852 \mathrm{~cm}^{-1}\left(-\mathrm{CH}_{3}\right.$ symmetric stretching), $1746 \mathrm{~cm}^{-1}$ (-C=O triglycerides carbonyl stretching), $1462 \mathrm{~cm}^{-1}\left(-\mathrm{CH}_{2}\right.$ antisymmetric deformation) and $1160 \mathrm{~cm}^{-1}$ (C-O stretching in the esters) [30-33]. 


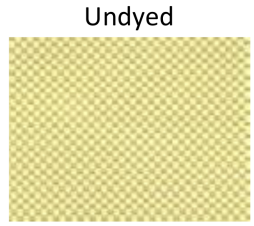

B11

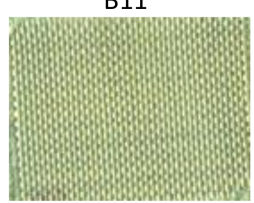

A7

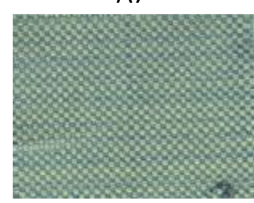

C3

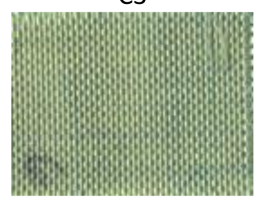

A9

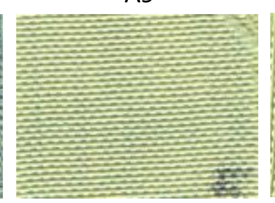

C9

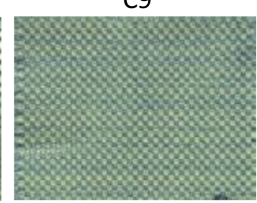

B3

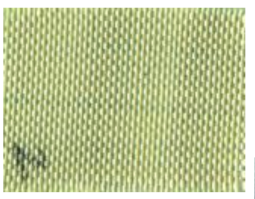

F15

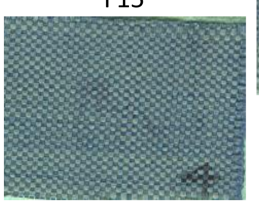

F15 (W2)

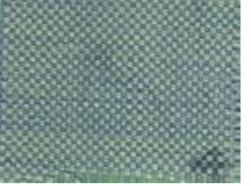

Figure 8. Scanned images comparing dyed samples with the undyed fabric (labels correspond to the sample numbers in Tables 1-5; F15 (W2) denotes sample F15 after second detergent wash).
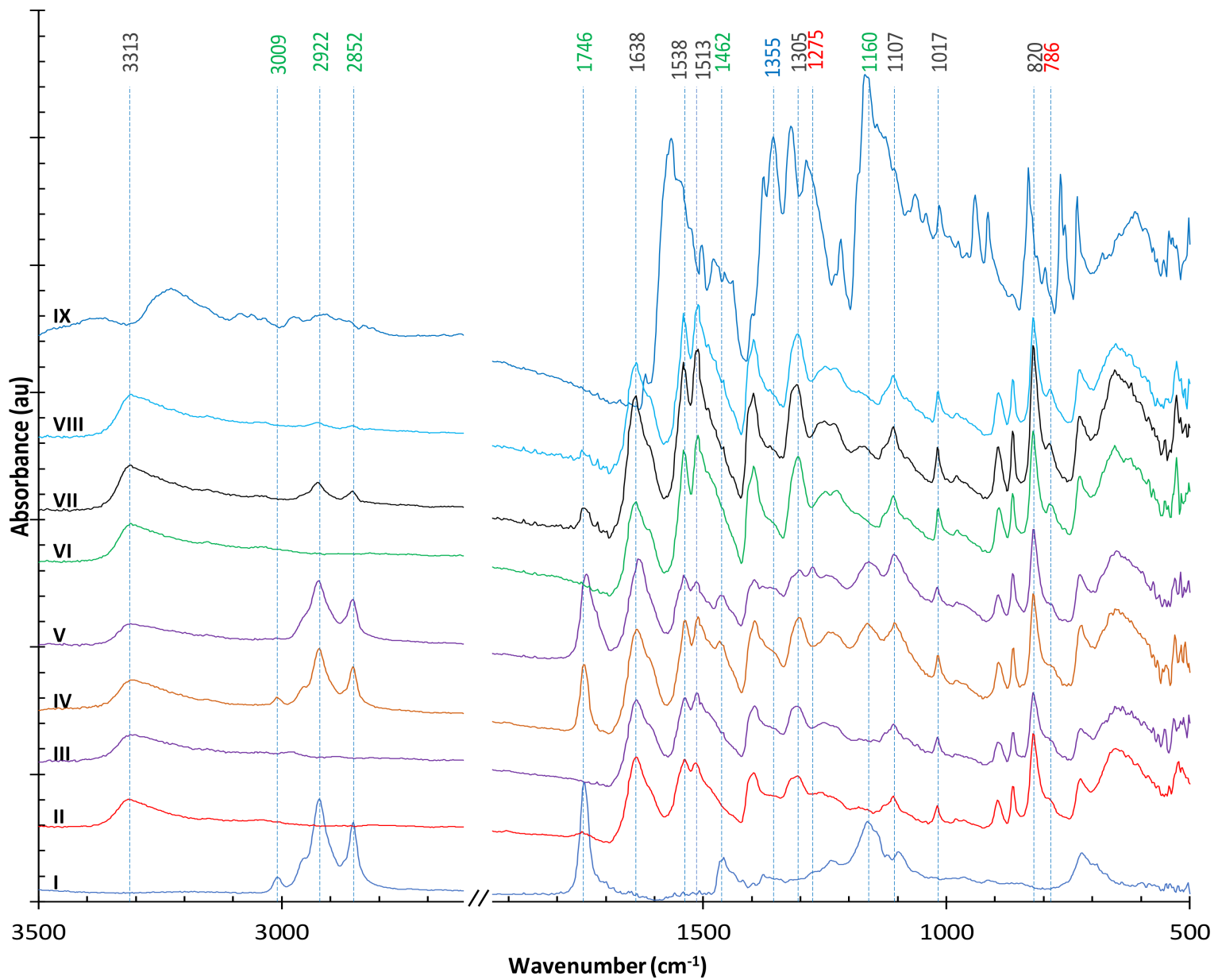

Figure 9. FTIR spectra of the para-aramid fabrics, materials and after certain treatments as follows: (I) Soybean oil; (II) Paraaramid fabric (untreated); (III) Para-aramid fabric treated with NTP; (IV) Para-aramid fabric after soaking in soybean oil; (V) Para-aramid fabric after soaking in soybean oil followed by a subsequent NTP treatment; (VI) Para-aramid fabric dyed with NTP as the only pretreatment; (VII) Para-aramid fabric dyed after soaking in soybean oil (without an NTP treatment); (VIII) Para-aramid fabric dyed after soaking in soybean oil and an NTP treatment; and (IX) Victoria Blue R cationic dye.

The spectrum of untreated para-aramids (line II) has main peaks at $3313 \mathrm{~cm}^{-1}(-\mathrm{N}-\mathrm{H}$ stretching), $1638 \mathrm{~cm}^{-1}$ (amide I C=O stretching) and $1538 \mathrm{~cm}^{-1}$ (-N-H deformation) [34]. The absorption bands at $1513 \mathrm{~cm}^{-1}$ (amide II), at $1017 \mathrm{~cm}^{-1}$ and at $820 \mathrm{~cm}^{-1}$ deriving from the $\mathrm{C}-\mathrm{H}$ bonds on the para-aromatic rings and the absorption band at $1305 \mathrm{~cm}^{-1}$ deriving 
from the $\mathrm{C}-\mathrm{N}$ bond stretch of amide III of the para-aramid fiber fabrics can be considered as internal standards for para-aramid [35]. NTP treatment of the para-aramid sample (line III) did not induce discernible changes in the observed FTIR peaks. A similar result was observed in Kašparová et al. [36], which also reported some changes in meta-aramids after NTP treatment and may reflect the different internal molecular structures between meta-aramids and para-aramids that make para-aramids more difficult to dye even with an NTP treatment.

The sample in line IV for the para-aramid fabric soaked in soybean oil shows peaks characteristic of soybean oil and of the para-aramids. Subsequent NTP treatment induces some important changes in the observed spectrum (line V). First, the unsaturated fatty acids peak at $3009 \mathrm{~cm}^{-1}$ decreases, but the other major characteristic peaks of soybean oil were still visible. This observation suggests that the double bonds in the unsaturated fatty acids were rapidly consumed by the NTP treatment, presumably by reaction with the plasma's reactive oxygen and nitrogen species (RONS). Second, there were changes in the $1380-1250 \mathrm{~cm}^{-1}$ region, including the formation of a small peak appearing at $1275 \mathrm{~cm}^{-1}$, which is assigned to the $\mathrm{C}-\mathrm{C}$ stretching vibration of the $\mathrm{C}-\mathrm{C}(=\mathrm{O})-\mathrm{C}$ groups in aliphatic ketone molecule [33]. These results suggest that the plasma's RONS attack the $\mathrm{C}=\mathrm{C}$ double bonds, concomitant to the decrease in the peak at $3009 \mathrm{~cm}^{-1}(=\mathrm{C}-\mathrm{H}$ stretching of aliphatic alkenes). However, the ketone molecule is unstable. A likely explanation is that high-energy reactive oxygen species in the NTP (generated with ambient air as the feedgas) attack the electron rich double bonds in the unsaturated fatty acids and form epoxides, although the characteristic oxirane absorption peak typically observed at $\sim 822$ $\mathrm{cm}^{-1}$ would be obscured by the strong para-aramid absorption peak at $820 \mathrm{~cm}^{-1}$. The $-\mathrm{C}=\mathrm{O}$ triglycerides carbonyl stretching and $\mathrm{C}-\mathrm{O}$ stretching in the esters at $1746 \mathrm{~cm}^{-1}$ and $1160 \mathrm{~cm}^{-1}$, respectively, remain strong in line V, indicating that the NTP did not break the ester bonds in soybean oil.

Strong acids such as phosphoric acid and sulfuric acid have been used to pretreat para-aramids for the improvement of dyeing or interfacial bonding; a new absorption peak at $\sim 3440 \mathrm{~cm}^{-1}$ (which is ascribed to the hydroxyl group $\mathrm{O}-\mathrm{H}$ ) or the shift and broadening of the $3313 \mathrm{~cm}^{-1}$ (-N-H stretching) band was reported, along with some decrease in mechanical strength. This distinct change was explained as a consequence of the increased number of $-\mathrm{OH}$ groups in the modified para-aramids due to hydrolysis [2,3]. However, this effect is not observed for the para-aramid sample pretreated with acetic acid in this study, and the acetic acid pretreatment did not significantly improve the color strength of dyeing.

FTIR spectra for dyed para-aramid fabric samples (Figure 9) are shown in line VI (with only NTP pretreatment), line VII (with soybean oil soaking but no NTP) and line VIII (with soybean oil soaking and NTP). The three spectra all have a new peak emerging at $786 \mathrm{~cm}^{-1}$, which is typically the region of $\mathrm{C}-\mathrm{H}$ bending for 1,3-disubstituted or 1,2,3trisubstituted aromatic rings, possibly indicating a new bond forming on the para-aromatic rings. Otherwise, the spectrum of the sample dyed only with NTP pretreatment (line VI) is not much different from that of undyed para-aramids (line II or III). The para-aramid fabric sample in line VII (pretreated with soybean oil soaking and without subsequent NTP treatment, showed peaks characteristic of soybean oil that were significantly diminished. NTP treatment after oil soaking induced further decreases in the signal intensity of soybean oil (line VIII). In addition to reactions with NTP, there are two possible explanations for the diminished oil signal: (1) unfixed oil could be washed off after dyeing and subsequent washing with detergent; and (2) the triacylglycerol could be hydrolyzed at the dyeing conditions resulting in the destruction of ester bonds, as indicated by the diminished peaks at $1746 \mathrm{~cm}^{-1}$ and $1160 \mathrm{~cm}^{-1}$.

The FTIR spectrum of the Victoria Blue R is also shown in Figure 9 (line IX). The para-aramid fabric samples showed a low uptake of dye, and most of the dye peaks were obscured by the characteristic peaks of the para-aramids and the oil. Accordingly, no 
significant dye peaks were detected in the dyed samples, except for a small shoulder at $1355 \mathrm{~cm}^{-1}$ in the spectra of the dyed samples (lines VII and VIII).

It is likely that the soybean oil well diffused throughout the tightly woven fabric and adsorbed onto the surfaces of yarns and fibers, and the NTP treatment induced the formation of a polymerized network in situ, enabling dyeing to a higher color strength. The unsaturated fatty acids in soybean oil play important roles in the dyeing process. Cross-linking/polymerization by the action of reactive plasma species are possible, because hydrogenation, nitration and epoxidation reactions have been observed along with polymerization under atmospheric NTP [37]. In a study on the tribological properties of air plasma polymerized soybean oil, Zhao et al. [33] concluded that the free radicals in the long-chain oil molecules, which were formed by the opening of the double bonds under the plasma conditions, could capture the reactive $\mathrm{O}$ and $\mathrm{N}$ species to produce and incorporate carbonyl, organic amine and nitrogen heterocyclic groups into the polymerized oil network. Moreover, depending on the duration of the NTP treatment in the dyeing procedure, the soybean oil might undergo processes such as complex oxidations, decomposition or fragmentation, to form reactive intermediate sites (e.g., ethers, furans, peroxides, carboxylic acids or 1,2,4-trioxolane [38,39]) on the para-aramid fiber fabrics that serve as catalysts or ligands to bind dye molecules.

\section{Conclusions}

Using a cationic dye and an environmentally friendly alternative dyeing method, we found that the best formulation for dyeing para-aramid textiles involved (i) pre-treating the para-aramid fiber fabrics with soybean oil followed by a brief NTP treatment, and (ii) using water at $\mathrm{T}=100^{\circ} \mathrm{C}$ as the dye solvent and omitting auxiliary chemical additives. Dyeing temperature and NTP treatment time were the most important factors, with the dyeing temperature of $\mathrm{T}=100{ }^{\circ} \mathrm{C}$ resulting in higher color strength (larger $\mathrm{K} / \mathrm{S}$ values), and the optimized NTP treatment time of $120 \mathrm{~s}$ for soybean oil pretreated para-aramids. These conditions achieved a K/S value up to 2.28 , which is significantly larger than the $\mathrm{K} / \mathrm{S} \sim 1$ for untreated samples. For comparison, NTP alone or the use of the auxiliary additives of acetic acid and benzyl alcohol only slightly improved dyeing with the cationic dye. As a dye solvent, glycerol was inferior to water for dyeing with the cationic dye, and the addition of the surfactant TWEEN 80 in the dye bath negatively impacted the dyeing performance.

In the present study, FTIR analysis revealed that NTP induced chemical reactions in soybean oil on the surface of para-aramid fabrics were responsible for significantly improving the color strength. These chemical reactions likely involved high-energy, shortlived reactive plasma species that first attacked the double bonds in the unsaturated fatty acids. While the results of this study provide ample evidence that the pretreatment of soaking in soybean oil and ensuing NTP treatment improved dyeing color strength, determining the chemical pathways that led to better dyeing warrant further research, to control these processes with other dyestuffs. Future research along this line of sustainable dyeing method will aim at deriving more functionalities of soybean oil on the surface of para-aramids to further improve the dyeing strength and colorfastness.

Author Contributions: Conceptualization, C.J.D. and X.P.Y.; methodology, X.P.Y. and C.J.D.; validation, X.P.Y. and M.M.; formal analysis, C.J.D. and X.P.Y.; investigation, M.M. and X.P.Y.; resources, C.J.D. and X.P.Y.; data curation, M.M.; writing—original draft preparation, X.P.Y.; writing—review and editing, X.P.Y. and C.J.D.; visualization, M.M. and X.P.Y.; supervision, X.P.Y.; project administration, C.J.D. and X.P.Y.; funding acquisition, C.J.D. and X.P.Y. All authors have read and agreed to the published version of the manuscript.

Funding: This work was partially supported by the Department of Agriculture HATCH project No. TEN00521.

Institutional Review Board Statement: Not applicable.

Informed Consent Statement: Not applicable. 
Data Availability Statement: The data presented in this study are available on request from the corresponding author.

Acknowledgments: We thank the support by the U.S. Department of Agriculture HATCH project No. TEN00521.

Conflicts of Interest: The authors declare no conflict of interest.

\section{References}

1. Roenbeck, M.R.; Sandoz-Rosado, E.J.; Cline, J.; Wu, V.; Moy, P.; Afshari, M.; Reichert, D.; Lustig, S.R.; Strawhecker, K.E. Probing the internal structures of Kevlar ${ }^{\circledR}$ fibers and their impacts on mechanical performance. Polymer 2017, 128, 200-210. [CrossRef]

2. Zhao, J. Effect of surface treatment on the structure and properties of para-aramid fibers by phosphoric acid. Fibers Polym. 2013, 14, 59-64. [CrossRef]

3. Xia, D.; Wang, L.J. Sulfuric Acid Treatment of Aramid Fiber for Improving the Cationic Dyeing Performance. Adv. Mater. Res. 2012, 627, 243-247. [CrossRef]

4. Vassiliadis, A.A.; Roulia, M.; Boussias, C.M. Disperse Dyeing Systems for p-aramid Fibers. In Proceedings of the 37th International Symposium on Novelties in Textiles, Ljubljana, Slovenia, 15-17 June 2006.

5. Dong, Y.; Jang, J. The enhanced cationic dyeability of ultraviolet/ozone-treated meta-aramid fabrics. Color. Technol. 2011, 127, 173-178. [CrossRef]

6. Jelil, R.A. A review of low-temperature plasma treatment of textile materials. J. Mater. Sci. 2015, 50, 5913-5943. [CrossRef]

7. Vu, N.; Michielsen, S. Near room temperature dyeing of m-aramid fabrics. J. Appl. Polym. Sci. 2019, 136, 48190. [CrossRef]

8. Han, S.Y.; Jaung, J.Y. Acid dyeing properties of meta-aramid fiber pretreated with PEO45-MeDMA derived from [2(methacryloyloxy)ethyl] trimethylammonium chloride. Fibers Polym. 2009, 10, 461-465. [CrossRef]

9. Xi, M.; Li, Y.-L.; Shang, S.-Y.; Li, D.-H.; Yin, Y.-X.; Dai, X.-Y. Surface modification of aramid fiber by air DBD plasma at atmospheric pressure with continuous on-line processing. Surf. Coat. Technol. 2008, 202, 6029-6033. [CrossRef]

10. Sun, Y.; Liang, Q.; Chi, H.; Zhang, Y.; Shi, Y.; Fang, D.; Li, F. The application of gas plasma technologies in surface modification of aramid fiber. Fibers Polym. 2014, 15, 1-7. [CrossRef]

11. Su, M.; Gu, A.; Liang, G.; Yuan, L. The effect of oxygen-plasma treatment on Kevlar fibers and the properties of Kevlar fibers/bismaleimide composites. Appl. Surf. Sci. 2011, 257, 3158-3167. [CrossRef]

12. Abou Elmaaty, T.; Eltaweel, F.; Elsisi, H. Water-free Dyeing of Polyester and Nylon 6 Fabrics with Novel 2-Oxoacetohydrazonoyl Cyanide Derivatives under a Supercritical Carbon Dioxide Medium. Fibers Polym. 2018, 19, 887-893. [CrossRef]

13. Kaul, B.L. Mass pigmentation and solution dyeing of synthetic fibres. In Synthetic Fibre Dyeing; Hawkyard, C., Ed.; Society of Dyers and Colourists: Bradford, West Yorkshire, UK, 2004; p. 230.

14. Kim, E.-M.; Choi, J.-H. Dyeing Properties and Color. Fastness of 100\% meta-Aramid Fiber. Fibers Polym. 2011, 12, 484-490. [CrossRef]

15. Ferrero, F.; Periolatto, M.; Rovero, G.; Giansetti, M. Alcohol-assisted dyeing processes: A chemical substitution study. J. Clean. Prod. 2011, 19, 1377-1384. [CrossRef]

16. Ferrero, F.; Periolatto, M. Glycerol in comparison with ethanol in alcohol-assisted dyeing. J. Clean. Prod. 2012, 33, 127-131. [CrossRef]

17. Pawar, S.S.; Maiti, S.; Biranje, S.; Kulkarni, K.; Adivarekar, R.V. A novel green approach for dyeing polyester using glycerine based eutectic solvent as a dyeing medium. Heliyon 2019, 5, e01606. [CrossRef] [PubMed]

18. Cheng, L.; Liu, L.; Ye, X.P. Acrolein Production from Crude Glycerol in Sub- and Super-Critical Water. J. Am. Oil Chem. Soc. 2013, 90, 601-610. [CrossRef]

19. Liu, L.; Ye, X.P. Simultaneous production of lactic acid and propylene glycol from glycerol using solid catalysts without external hydrogen. Fuel Process. Technol. 2015, 137, 55-65. [CrossRef]

20. Liu, L.; Ye, X.P.; Bozell, J.J. A Comparative Review of Petroleum-Based and Bio-Based Acrolein Production. ChemSusChem 2012, 5 , 1162-1180. [CrossRef]

21. Zou, B.; Ren, S.; Ye, X.P. Glycerol Dehydration to Acrolein Catalyzed by ZSM-5 Zeolite in Supercritical Carbon Dioxide Medium. ChemSusChem 2016, 9, 3268-3271. [CrossRef]

22. Baliarsingh, S.; Jena, J.; Das, T.; Das, N.B. Role of cationic and anionic surfactants in textile dyeing with natural dyes extracted from waste plant materials and their potential antimicrobial properties. Ind. Crops Prod. 2013, 50, 618-624. [CrossRef]

23. Gur-Arieh, Z.; Ingamells, W. The Role of Benzyl Alcohol in the Solvent-assisted Dyeing of Acrylic Fibres. J. Soc. Dye. Colour. 2008, 90, 8-11. [CrossRef]

24. Shao, D.; Xu, C.; Wang, H.; Du, J. Enhancing the Dyeability of Polyimide Fibers with the Assistance of Swelling Agents. Materials 2019, 12, 347. [CrossRef] [PubMed]

25. Nechwatal, A.; Rossbach, V. The Carrier Effect in the m-Aramid Fiber/Cationic Dye/Benzyl Alcohol System. Text. Res. J. 1999, 69, 635-641. [CrossRef]

26. Zheng, H.-D.; Zhang, J.; Yan, J.; Zheng, L.-J. Investigations on the effect of carriers on meta-aramid fabric dyeing properties in supercritical carbon dioxide. RSC Adv. 2017, 7, 3470-3479. [CrossRef] 
27. Morris, M.; Ye, X.P.; Doona, C.J. Soybean Oil and Nonthermal Plasma Pretreatment to Dye Para-Aramid Woven Fabrics with Disperse Dye Using a Glycerol-Based Dye Bath. J. Am. Oil Chem. Soc. 2021, 98, 463-473. [CrossRef]

28. Standard, ISO 105-C10:2006. Colour Fastness to Washing with Soap or Soap and Soda. In Textiles-Tests for Colour Fastness. In Internaltional Standardisation Organisation; Internaltional Standardisation Organisation: Geneva, Switzerland, 2006.

29. Etters, J.N.; Hurwitz, M.D. Opaque reflectance of translucent fabric. Text. Chem. Color. 1986, 18, 19-26.

30. Lumakso, F.; Rohman, A.M.H.; Riyanto, S.; Yusof, F. Detection and quantification of soybean and corn oils as adulterants in avocado oil using fourier transform mid infrared (FT-MIR) spectroscopy aided with multivariate calibration. J. Teknol. 2015, 77, 251-255. [CrossRef]

31. Man, Y.; Rohman, A. Analysis of Canola Oil in Virgin Coconut Oil Using FTIR Spectroscopy and Chemometrics. J. Food Pharm. Sci. 2013, 1, 5-9.

32. Sienkiewicz, A.M.; Czub, P. The unique activity of catalyst in the epoxidation of soybean oil and following reaction of epoxidized product with bisphenol A. Ind. Crops Prod. 2016, 83, 755-773. [CrossRef]

33. Zhao, X.; Yang, J.; Tao, D.; Xu, X. Synthesis and Tribological Properties of Air Plasma Polymerized Soybean Oil with N-Containing Structures. J. Am. Oil Chem. Soc. 2014, 91, 827-837. [CrossRef]

34. Haijuan, K.; Hui, S.; Jin, C.; Haiquan, D.; Xiaoma, D.; Mengmeng, Q.; Muhuo, Y.; Youfeng, Z. Improvement of adhesion of kevlar fabrics to epoxy by surface modification with acetic anhydride in supercritical carbon dioxide. Polym. Compos. 2019, 40, E920-E927. [CrossRef]

35. Mukherjee, M.; Kumar, S.; Bose, S.; Das, C.; Kharitonov, A. Study on the Mechanical, Rheological, and Morphological Properties of Short Kevlar ${ }^{\mathrm{TM}}$ Fiber/s-PS Composites. Polym. Plast. Technol. Eng. 2008, 47, 623-629. [CrossRef]

36. Kašparová, M.; Šašková, J.; Gregr, J.; Wiener, J. Using of DSCBD plasma for treatment of Kevlar and Nomex fibers. Chem. Listy 2008, 102, 1515-1518.

37. Ximena, V.Y. Characterization and Analysis of High Voltage Atmospheric Cold Plasma Treatment of Soilbean Oil. Ph.D. Thesis, Purdue University, West Lafayette, IN, USA, 2020.

38. Van Durme, J.; Nikiforov, A.; Vandamme, J.; Leys, C.; De Winne, A. Accelerated lipid oxidation using non-thermal plasma technology: Evaluation of volatile compounds. Food Res. Int. 2014, 62, 868-876. [CrossRef]

39. Zou, X.; Xu, M.; Pan, S.; Gan, L.; Zhang, S.; Chen, H.; Liu, D.; Lu, X.; Ostrikov, K.K. Plasma Activated Oil: Fast Production, Reactivity, Stability, and Wound Healing Application. ACS Biomater. Sci. Eng. 2019, 5, 1611-1622. [CrossRef] [PubMed] 